\title{
ENRAIZAMENTO DE ESTACAS DE PESSEGUEIRO EM FUNÇÃO DO USO DE ÁCIDO INDOLBUTÍRICO E FERTILIZANTE ORGẨNICO'
}

\author{
UBIRAJARA RIBEIRO MINDÊLLO NETO²
}

\begin{abstract}
RESUMO - Este trabalho teve como objetivo avaliar o efeito de concentrações de ácido indolbutírico e do fertilizante orgânico HFF turfa fértilß no enraizamento de estacas semilenhosas do pessegueiro 'Capdeboscq'. Estacas foram tratadas com AIB em concentrações de 500; $1.000 ; 2.000$ e 4.000 $\mathrm{mg} . \mathrm{L}^{-1} \mathrm{e}$ água destilada como testemunha $\left(0 \mathrm{mg} . \mathrm{L}^{-1}\right)$. Posteriormente, as estacas foram acondicionadas em bandejas de poliestireno expandido com 72 células, contendo como substrato vermiculita, e colocadas em câmara de nebulização intermitente. Aos 30 dias após o início do experimento, foi colocado o fertilizante orgânico HFF turfa fértil ${ }^{\circledR}$ em concentrações de $0 \mathrm{~mL} . \mathrm{L}^{-1}, 3 \mathrm{~mL} . \mathrm{L}^{-1} \mathrm{e} 5 \mathrm{~mL} . \mathrm{L}^{-1}$ nas células onde estavam contidas as estacas. Após 86 dias do início do experimento, foram avaliados a porcentagem de estacas enraizadas e o número médio de raízes por estaca. A aplicação de HFF turfa fértil@ em associação ao ácido indolbutírico promoveu maior enraizamento em relação aos tratamentos sem o uso do fertilizante orgânico. A maior porcentagem de estacas de pessegueiro enraizadas foi obtida com a combinação de $2.000 \mathrm{mg} . \mathrm{L}^{-1}$ de AIB e 5 mL.L $\mathrm{L}^{-1}$ de HFF turfa fértilß.
\end{abstract}

Termos para indexação: Prunus persica (L.) Batsch, estaquia, auxina e HFF turfa fértil®.

\section{ROOTING OF PEACH CUTTINGS IN FUNCTION OF THE USE OF INDOLBUTYRIC ACID AND ORGANIC FERTILIZER}

\begin{abstract}
This work aim to appraise the effect of indolbutyric acid (IBA) and HFF turfa fértil® organic fertilizer concentrations on rooting of semihardwood cuttings of peach 'Capdebosq'. The cuttings were treated by IBA at 500; 1,000; 2,000 and 4,000 mg.L.-1 and destilled water $(0$ mg.L-1) as witness. Later on the cuttings were planted in expanded polyestirene trays with 72 cells using vermiculite as substrate and placed inside intermitent mist chamber. At 30 days after the beginning of the experiment was places the HFF turfa fértil ${ }^{\circledR}$ organic fertilizer at concentrations of 0,3 and $5 \mathrm{~mL}$. $\mathrm{L}^{-}$ ${ }^{1}$ on the tray cells. At 86 days were evaluated the rooted cuttings percentage and the average number of roots per cuttings. The use of HFF turfa fértil ${ }^{\circledR}$ in association with $\mathrm{IAB}$ promoted higher rooting in relation of treatments without the organic fertilizer. The higher percentage of peach rooted cuttings were obtained with a combination of $2,000 \mathrm{mg} \cdot \mathrm{L}^{-1}$ of AIB and $5 \mathrm{~mL} \cdot \mathrm{L}^{-1}$ of HFF turfa fértil@.
\end{abstract}

Index Terms: Prunus persica (L.) Batsch, cuttings, auxin and HFF turfa fértil®.

\section{INTRODUÇÃO}

A produção brasileira de pêssegos no ano de 2001 foi de 222.636 ton. Essa produção ainda é insuficiente para suprir a demanda de frutos desta cultura. As importações brasileiras no ano de 2002 foram de 3.980 e 7.031 ton, respectivamente, para pêssego in natura e em calda (Agrianual, 2004). Para reverter este quadro e tornar o Brasil autosustentável na produção de pêssego, o desenvolvimento de novas tecnologias é fundamental para o aumento da produtividade e da rentabilidade. Assim, novas alternativas no processo de propagação que aumentem a oferta de mudas, poderão incentivar o aumento da área de plantio desta frutífera e, conseqüentemente, o incremento da produção desta fruta no mercado.

Os principais métodos de propagação do pessegueiro são por sementes (reprodução sexuada), enxertia e estaquia (reprodução assexuada). Atualmente, a propagação é feita basicamente por meio da enxertia de borbulhas sobre porta-enxertos oriundas de sementes (Fachinello et al., 1995).

O uso de porta-enxertos originados de sementes não é aconselhável, pois pode haver perda de características genéticas desejáveis, gerando indivíduos distintos da planta-matriz (Chalfun et al., 1994; Pasinato et al., 1998). A enxertia também apresenta inconvenientes, como maior tempo de produção de mudas, necessidade de mão-de-obra especializada para operação, risco de segregação genética dos porta-enxertos e vida útil produtiva da copa limitada pela longevidade do material utilizado como porta-enxerto, normalmente entre 12 e 14 anos (Kersten, 1991; Pasinato et al., 1998). Com o uso da estaquia, tanto para produção de porta-enxertos, quanto de copas, evitam-se estes inconvenientes, pois não há a necessidade de enxertia, diminuindo o custo e o tempo para a produção da muda, além da uniformidade de sua descendência, gerando pomares homogêneos (Chalfun \& Hoffmann, 1997).

O método de propagação por estaquia, apesar de ser interessante, às vezes é inviável para algumas espécies de difícil enraizamento. Para melhorar esta técnica, tem se recorrido à aplicação de reguladores de crescimento, tais como o ácido indolbutírico (AIB) (Fachinello et al., 1995; Dutra et al., 1998).

Fachinello et al. (1984) observaram que o AIB influenciou na porcentagem de estacas lenhosas enraizadas de pessegueiro 'Capdeboscq' e constataram que o máximo de enraizamento $(68,9 \%)$ ocorreu com $2.790 \mathrm{mg} . \mathrm{L}^{-1}$. Dutra et al. (1999) utilizaram cinco concentrações de $\operatorname{AIB}\left(0 ; 1.000 ; 2.000 ; 3.000\right.$ e $\left.4.000 \mathrm{mg} . \mathrm{L}^{-1}\right)$ no enraizamento de estacas semilenhosas de três cultivares de pessegueiro (Diamante, BR-2 e Capdeboscq) e verificaram que a maior porcentagem de estacas enraizadas (36,65\%) foi obtida com $2.318 \mathrm{mg} . \mathrm{L}^{-1}$ de AIB.

Em relação ao efeito de fertilizantes orgânicos no enraizamento de estacas, os estudos estão voltados para a influência dos carboidratos e a sua relação com a formação de raízes adventícias.

Em diversos trabalhos, foi demonstrada a necessidade de equilíbrio entre auxina e carboidratos para a ótima produção de raízes, pois, durante o processo de enraizamento, ocorre drenagem contínua de amido e açúcares solúveis através da parte basal da estaca (Bhattacharya et al., 1985). A relação entre o conteúdo de carbono e nitrogênio pode estar relacionada com a habilidade de enraizar, conforme relatou Veierskov (1988). Os carboidratos podem também exercer outras funções na indução ao enraizamento, influenciando na osmorregulação, na capacidade solvente das células e em outros fenômenos fisioquímicos (Haissig, 1988).

O objetivo do presente trabalho foi avaliar a influência de concentrações de AIB e do fertilizante orgânico HFF turfa fértil ${ }^{\circledR}$ no enraizamento de estacas semilenhosas de pessegueiro cv. Capdeboscq.

\section{MATERIAL E MÉTODOS}

O experimento foi conduzido no período de março a junho de 2004, na EMBRAPA Transferência de Tecnologia/SNT, localizada no município de Canoinhas-SC, em câmara de nebulização intermitente, controlada por "timer", com intervalo e tempo de irrigação,

\footnotetext{
${ }^{1}$ (Trabalho 112/2004). Recebido: 21/09/2004. Aceito para publicação: 09/03/2005.

${ }^{2}$ Eng. Agr. M.Sc. Embrapa Transferência de Tecnologia/SNT Canoinhas, Rod. BR. 280, km 219, Caixa Postal 317, CEP 89 460-000, Canoinhas-SC, Fone: (47) 6240127; ubirajara.encan@embrapa.br.
} 
respectivamente, de 15 minutos e 20 segundos.

Estacas semilenhosas foram coletadas de plantas-matrizes com dois anos de idade e levadas para laboratório para serem padronizadas em comprimento de $15 \mathrm{~cm}$ e diâmetro entre 6 e $8 \mathrm{~mm}$, mantendo-se 4 folhas cortadas ao meio no terço superior de cada estaca. Antes de as estacas serem tratadas com o regulador de crescimento, elas foram submetidas a tratamento fitossanitário com fungicida (captan a 0,25\%). Posteriormente, todas as estacas foram submetidas à raspagem, cerca de $2 \mathrm{~cm}$ na sua parte basal, em ambos os lados, para exposição do câmbio.

As estacas foram tratadas com AIB, cujas concentrações foram dissolvidas em álcool etílico e diluídas em água destilada, na proporção de 1:1 (álcool:água destilada). Foram utilizadas as concentrações de 0 ; 500; $1.000 ; 2.000$ e $4.000 \mathrm{mg} . \mathrm{L}^{-1}$ de AIB, sendo que, na concentração de 0 $\mathrm{mg} . \mathrm{L}^{-1}$, foi utilizada apenas água destilada (testemunha). O método de aplicação, tanto das soluções do regulador de crescimento, como da água destilada foi por imersão da parte basal das estacas por 5 segundos. Em seguida, as estacas foram colocadas em bandejas de poliestireno expandido com 72 células, contendo como substrato vermiculita de grânulos médios.

A aplicação do fertilizante orgânico foi efetuada 30 dias após o início do experimento, utilizando o produto HFF turfa fértil@ da empresa Florestal S.A. O produto é líquido e apresenta a seguinte composição química: densidade $(1,2 \mathrm{~g} / \mathrm{mL})$, umidade a $105^{\circ}(63,2 \%), \mathrm{N}$ total $(4 \%), \mathrm{P}$ total (10\%), K total (6\%), C total (35,17\%), relação C/N (4/1) e Ácidos Húmicos (15\%). As concentrações do fertilizante orgânico utilizados neste trabalho foram diluídas em água destilada $\left(0 \mathrm{~mL} . \mathrm{L}^{-1}, 3 \mathrm{~mL} . \mathrm{L}^{-1}\right.$ e 5 $\left.\mathrm{mL} \cdot \mathrm{L}^{-1}\right)$. Após o preparo destas soluções, foram retirados 0,3 e $5 \mathrm{~mL}$, respectivamente, de cada solução e aplicados nos respectivos tratamentos por meio de uma proveta, em cada célula onde estavam as estacas.

O delineamento experimental foi o inteiramente casualizado, em arranjo fatorial 5 x 3 (concentrações de AIB x concentrações de HFF turfa fértil $\left.{ }^{\circledR}\right)$, com 4 repetições, sendo as unidades experimentais formadas por 12 estacas, perfazendo um total de 48 estacas por tratamento. Após 86 dias do início do experimento, foram avaliados a porcentagem de estacas enraizadas e o número médio de raízes por estaca. Os resultados foram submetidos à análise de variância e as médias comparadas pelo teste de Scott-Knott, a 5\% de probabilidade.

\section{RESULTADOSE DISCUSSÃO}

Conforme se observa na Tabela 1, houve influência dos fatores concentração de AIB e fertilizante orgânico na porcentagem de estacas enraizadas. Observa-se que, nas estacas que não foram tratadas com o regulador de crescimento, o enraizamento foi nulo; entretanto, quando aplicado aos 30 dias, $5 \mathrm{~mL}$. $\mathrm{L}^{-1}$ de HFF turfa fértil $®$, ocorreu enraizamento, mesmo com baixo percentual de estacas enraizadas. Isto demonstra que o uso do fertilizante orgânico, mesmo em ausência de AIB, promove a formação de raízes, mas não o suficiente para alcançar porcentagens razoáveis de enraizamento.

TABELA 1 - Porcentagem de estacas semilenhosas enraizadas de pessegueiro cv. Capdeboscq, em função de concentrações de AIB e HFF turfa fértil® .

\begin{tabular}{crrr}
\hline \multicolumn{5}{c}{ Concentração de HFF turfa fértil® $\left(\mathrm{ml.} \mathrm{L}^{-1}\right)^{1}$} \\
\hline $\begin{array}{c}\text { Concentração de } \\
\left.\text { AIB (mg.L }{ }^{-1}\right)\end{array}$ & 0 & 3 \\
\hline 0 & $0,00 \mathrm{~B} \mathrm{~b}$ & $0,00 \mathrm{C} \mathrm{b}$ & $18,75 \mathrm{~B} \mathrm{a}$ \\
500 & $41,66 \mathrm{~A} \mathrm{c}$ & $60,41 \mathrm{~B} \mathrm{~b}$ & $93,75 \mathrm{~A} \mathrm{a}$ \\
1.000 & $45,83 \mathrm{~A} \mathrm{c}$ & $83,33 \mathrm{~A} \mathrm{~b}$ & $95,83 \mathrm{~A} \mathrm{a}$ \\
2.000 & $31,25 \mathrm{~A} \mathrm{c}$ & $79,16 \mathrm{~A} \mathrm{~b}$ & $100,00 \mathrm{~A} \mathrm{a}$ \\
4.000 & $8,33 \mathrm{~B} \mathrm{c}$ & $77,08 \mathrm{~A} \mathrm{~b}$ & $89,58 \mathrm{~A} \mathrm{a}$ \\
\hline C.V.(\%) & & 15,74 \\
\hline
\end{tabular}

${ }^{1}$ Médias seguidas de mesma letra maiúscula, na coluna, e minúscula, na linha, não diferem significativamente entre si, ao nível de $5 \%$ de probabilidade, pelo teste de Scott-Knott.
Em todas as concentrações de AIB usadas e associadas com o HFF turfa fértil®, a porcentagem de estacas enraizadas aumentou em relação aos tratamentos em que não foi feita aplicação do fertilizante orgânico (Tabela 1). Isto sugere que os elementos que compõem o produto orgânico, de certa forma, devem ter aumentado o conteúdo de carboidratos nas estacas, favorecendo o enraizamento, estando de acordo com a literatura citada (Bhattacharya et al., 1985; Veierskov, 1988; Fachinello et al., 1995).

Pode-se observar ainda que o enraizamento foi máximo com a combinação de $5 \mathrm{~mL}$. $\mathrm{L}^{-1}$ de HFF turfa fértil® e $2.000 \mathrm{mg} . \mathrm{L}^{-1}$ de AIB (Tabela 1). Estes resultados demonstram o efeito sinérgico de fertilizantes orgânicos e reguladores de crescimento no enraizamento deste portaenxerto.

Fachinello et al. (1984) e Dutra et al. (1999), na propagação por estaquia do pessegueiro cultivar Capdebosq, obtiveram máximo enraizamento inferior ao do presente trabalho, quando as estacas foram tratadas com a concentração de $5 \mathrm{~mL}$. $\mathrm{L}^{-1}$ de HFF turfa fértil ${ }^{\circledR}$ em associação ao AIB (Tabela 1).

A aplicação de HFF turfa fértil@ aos 30 dias após o início do experimento, em concentrações de 3 e $5 \mathrm{~mL}$. $\mathrm{L}^{-1}$ e associado ao AIB, promoveu maior número de raízes, em comparação à testemunha, sendo que os melhores resultados foram obtidos com a concentração de 2.000 mg.L $\mathrm{L}^{-1}$ de AIB e $5 \mathrm{~mL}$. $\mathrm{L}^{-1}$ de HFF turfa fértil® (Tabela 2). O fato, na cultivar Capdeboscq, de ter demonstrado maior capacidade de emissão de raízes quando aplicado o fertilizante orgânico, provavelmente, se deve ao equilíbrio ocorrido entre a auxina exógena e os carboidratos formados no processo de enraizamento, permitindo maior produção de raízes.

TABELA 2 - Número médio de raízes nas estacas, em função de concentrações de AIB e HFF turfa fértil®.

\begin{tabular}{|c|c|c|c|}
\hline & \multicolumn{3}{|c|}{ Concentração de HFF turfa f értil ${ }^{\circledR}\left(\mathrm{ml} \mathrm{L}^{-1}\right)$} \\
\hline $\begin{array}{l}\text { Concentração } \\
\text { de AIB }\left(\mathrm{mg}^{\left.-L^{-1}\right)}\right.\end{array}$ & 0 & 3 & 5 \\
\hline 0 & $0,00 \mathrm{Ab}$ & $0,00 \mathrm{Db}$ & $0,75 \mathrm{E} \mathrm{a}$ \\
\hline 500 & $3,16 \mathrm{~A} \mathrm{c}$ & $5,45 \mathrm{C} \mathrm{b}$ & $12,08 \mathrm{D}$ a \\
\hline 1.000 & $5,47 \mathrm{~A} \mathrm{c}$ & $9,94 \mathrm{~B} \mathrm{~b}$ & $14,66 \mathrm{C} \mathrm{a}$ \\
\hline 2.000 & $2,87 \mathrm{~A} \mathrm{c}$ & $14,98 \mathrm{Ab}$ & $19,04 \mathrm{~A} \mathrm{a}$ \\
\hline 4.000 & $1,02 \mathrm{~A} \mathrm{c}$ & $14,95 \mathrm{~A} \mathrm{~b}$ & $15,70 \mathrm{~B} \mathrm{a}$ \\
\hline C.V.(\%) & & 18,49 & \\
\hline
\end{tabular}

${ }^{1}$ Médias seguidas de mesma letra maiúscula, na coluna, e minúscula, na linha, não diferem significativamente entre si, ao nível de 5\% de probabilidade, pelo teste de Scott-Knott.

\section{CONCLUSÕES}

1. A aplicação de HFF turfa fértil® aos 30 dias após o início do experimento promoveu maior porcentagem de estacas enraizadas e número de raízes, em comparação à testemunha.

2. O tratamento que obteve melhores resultados, foi com a concentração de $2.000 \mathrm{mg} . \mathrm{L}^{-1}$ de AIB e $5 \mathrm{~mL}$. $\mathrm{L}^{-1}$ de HFF turfa fértil®.

\section{AGRADECIMENTOS}

O autor agradece à Empresa Florestal S/A e aos Engenheiros Agrônomos Amilcar Seus Ferreira e Ricardo Munoz da Silva, pelo fornecimento do fertilizante orgânico HFF turfa fértil ${ }^{\circledR}$ e pelas informações técnicas do produto, para a realização do presente trabalho.

\section{REFERÊNCIAS}

AGRIANUAL: Anuário de agricultura brasileira. São Paulo: FNP Consultoria e Comércio, 2004. 409p.

BHATTACHARYA, S.; BHATTACHARYA, N. C.; STRAIN, B. R. Rooting of sweet potato stem cuttings under $\mathrm{CO} 2$ enriched environment and with IAA treatment. Hortscience, Alexandria, v. 20, n. 6, p. 1109- 
$1110,1985$.

CHALFUN, N. N. J; PASQUAL, M.; RAMOS, J. D.; LIMA, P. C.; CHALFUN JÚNIOR, A.; SILVA, T. das G. Efeito do anelamento e diferentes dosagens do ácido indolbutírico na propagação de estacas caulinares do pessegueiro "Okinawa". Revista Brasileira de Fruticultura, Cruz das Almas, v. 16, n. 1, p. 119-126, 1994.

CHALFUN, N. N. J.; HOFFMANN, A. Propagação do pessegueiro e da ameixeira. Informe Agropecuário, Belo Horizonte, v. 18, n. 189, p. 23 29, 1997.

DUTRA, L. F.; TONIETTO, A.; KERSTEN, E. Efeito da aplicação de ethefon em ameixeira (Prunus salicina Lindl) e do IBA no enraizamento de suas estacas. Scientia Agricola, Piracicaba, v. 55, n. 2, p. 296-304, 1998.

DUTRA, L. F.; SCHWENGBER, J. E.; TONIETTO, A.; KERSTEN, E. Enraizamento de estacas de pessegueiro (Prunus persica (L.) Batsch). Revista Brasileira de Agrociência, Pelotas, v. 5, n. 2, p. 93 95, 1999.

FACHINELLO, J. C; KERSTEN, E.; SILVEIRAJÚNIOR, P. Efeito do ácido indolbutírico na percentagem de estacas lenhosas enraizadas e na obtenção de mudas de pessegueiro (Prunus persica (L.) Batsch). In: CONGRESSO BRASILEIRO DE FRUTICULTURA, 7., 1984,
Florianópolis. Anais... Florianópolis: Sociedade Brasileira de Fruticultura, 1984. p. 1088-1096.

FACHINELLO, J. C.; HOFFMANN, A.; NACHTIGAL, J. C. et al. Propagação de plantas frutíferas de clima temperado. 2.ed. Pelotas: Ufpel, 1995. 178p.

HAISSIG, B. E.; RIEMENSCHNEIDER, E. D. Genetic effects on adventitious rooting. In: DAVIS, T. D.; HAISSIG, B. E.; SANKLHA, N. (Ed.). Adventitious root formation in cuttings. Portland: Discorides Press, 1988, p.47-60.

KERSTEN, E. Efeito do boro, zinco e ácido indolbutírico no enraizamento de estacas de dois cultivares de ameixeira (Prunus salicina, Lindl.). 1991. 109f. Tese (Doutorado em Solos e Nutrição de Plantas) - Escola Superior de Agricultura Luiz de Queiroz, Piracicaba, 1991.

PASINATO, V.; NACHTIGAL, J. C.; KERSTEN, E. Enraizamento de estacas lenhosas de cultivares de ameixeira (Prunus spp.), em condições de campo. Scientia Agricola, Piracicaba, v. 55, n. 2, p.265268, maio/ago. 1998.

VEIERSKOV, B. Relations between carbohydrates and adventitious root formation. In: DAVIES, T. D.; HAISSIG, B. E; SANKHLA, N. Adventitious root formation in cuttings. Portland: Dioscorides Press, 1988. p.70-78. 